\title{
Successful implantation of a Berlin heart biventricular assist device in a failing single ventricle
}

\author{
Meena Nathan, MD, Christopher Baird, MD, Francis Fynn-Thompson, MD, Christopher Almond, MD, MPH, \\ Ravi Thiagarajan, MD, MPH, Peter Laussen, MBBS, Elizabeth Blume, MD, and Frank Pigula, MD, Boston, Mass
}

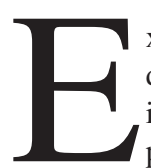

xtracorporeal membrane oxygenation (ECMO) has traditionally been used for short-term mechanical support in pediatric cardiac failure, but its utility is limited by prolonged waiting times for allografts. Ventricular assist devices (VADs) are being used with increasing frequency in children as a long-term bridge to transplantation. We report our experience with placement of a biventricular assist device (BIVAD) in a child with failing Fontan circulation as a bridge to transplantation.

\section{Clinical Summary}

A 4-year-old, 12-kg girl with hypoplastic left heart syndrome and a failing Fontan circulation was admitted with pleural effusions, plastic bronchitis, systemic venous hypertension, and extensive systemicto-pulmonary arterial collaterals. At catheterization (Figure 1), her calculated pulmonary vascular resistance was 3.8 WU. Despite maximal medical management, her condition rapidly deteriorated, requiring urgent ECMO cannulation through the right neck vessels.

After 7 days of ECMO, conversion to VAD support as a bridge to transplantation was performed. A 30-mL Berlin Heart left VAD

From the Department of Cardiac Surgery, Children's Hospital, Boston, Harvard Medical School, Boston, Mass.

Received for publication Feb 3, 2006; revisions received Feb 15, 2006; accepted for publication Feb 20, 2006.

Address for reprints: Frank Pigula, MD, Children's Hospital, Cardiac Surgery, Bader 273, 300 Longwood Ave, Boston, MA 02115.

J Thorac Cardiovasc Surg 2006;131:1407-8

$0022-5223 / \$ 32.00$

Copyright () 2006 by The American Association for Thoracic Surgery doi:10.1016/j.jtcvs.2006.02.015 was inserted from the systemic ventricular apex to the aorta. Persistent systemic venous hypertension necessitated placement of a 25-mL right VAD (RVAD). Separation of systemic and pulmonary circulations was accomplished by taking down the cavopulmonary anastomosis, re-establishing superior vena cava to right atrium continuity, and repairing the pulmonary arteries. The Fontan baffle fenestration was closed. RVAD inflow was provided by means of direct cannulation of the right atrial wall into the Fontan baffle, and an outflow cannula was inserted into the pulmonary arteries (Figure 2). Postoperatively, she remained hemodynamically stable and neurologically intact. Systemic venous pressures remained increased, despite optimizing medical management and pump performance. Cardiac catheterization on postoperative day 25 showed systemic venous hypertension $(25 \mathrm{~mm} \mathrm{Hg})$ and increased ventricular end-diastolic pressures $(23 \mathrm{~mm} \mathrm{Hg})$. On day 28 of BIVAD support, heart transplantation was performed, which was complicated by primary graft failure requiring ECMO. She died 8 days after transplantation from multisystem organ failure.

\section{Discussion}

Management of failing Fontan circulation presents a formidable challenge. Results of heart transplantation from ECMO have been poor. ${ }^{1}$ Other strategies have therefore been pursued. The Berlin heart, a pneumatically driven paracorporeal device, has been successfully used to bridge children with biventricular failure to heart transplantation, but there is little experience with its use in failing single ventricles. ${ }^{2}$

Failure of single ventricle circulation is largely unique to children and young adults. Implantable VADs in failing single ventricle circulation have the potential to allow circulatory, metabolic,

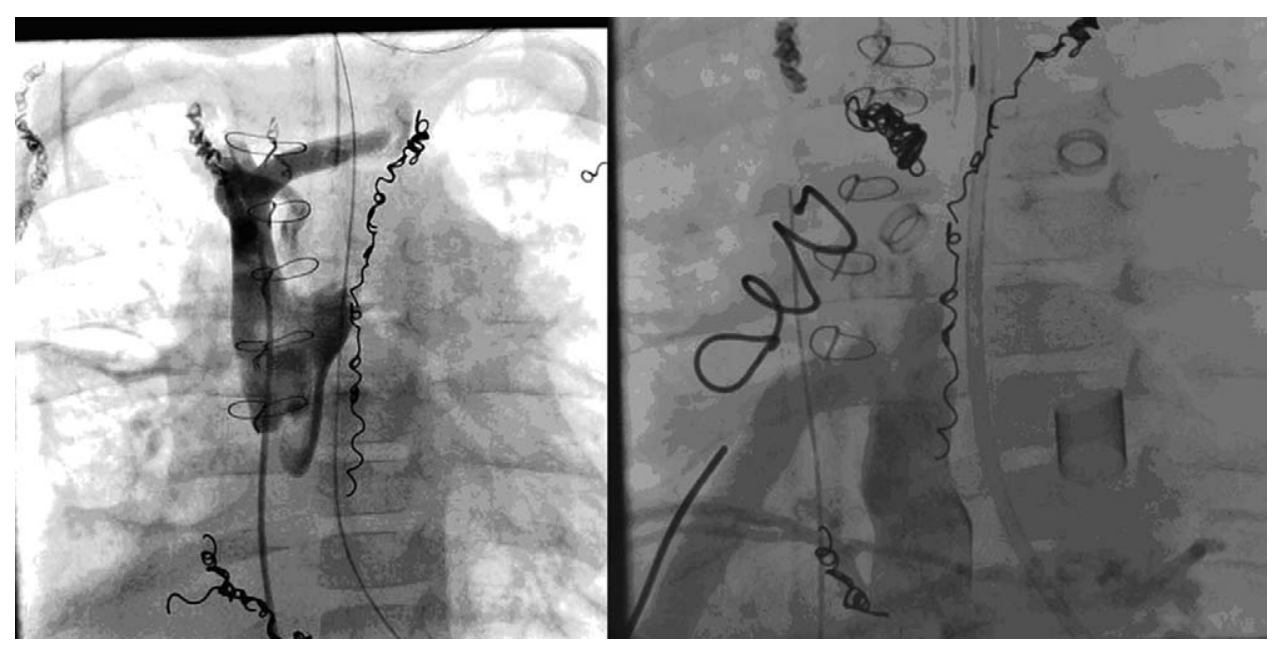

Figure 1. Preoperative and postoperative catheterization. 

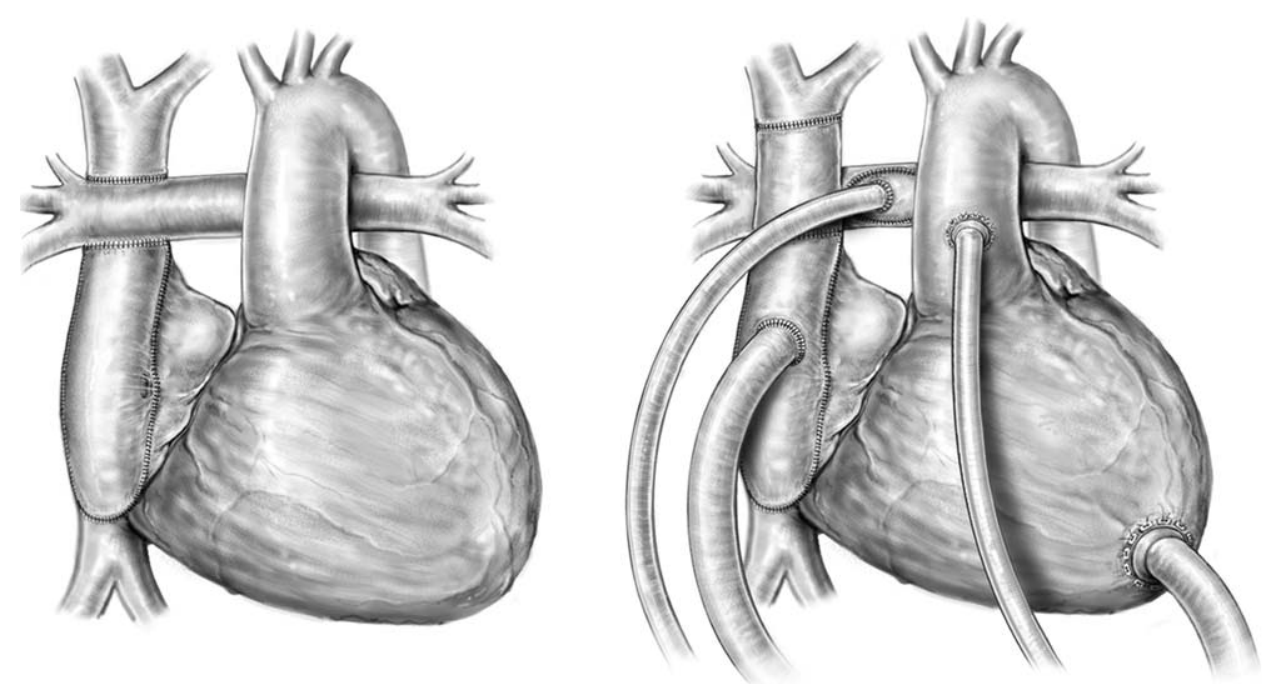

Figure 2. Schematic of the patient's Fontan circulation and biventricular assist device cannulation.

and pulmonary rehabilitation. However, implantation of these devices requires modification of standard techniques, as described.

Persistent systemic venous hypertension in this patient was a significant morbidity. At the time of explantation, a clot was found within the RVAD inflow cannula orifice, and this might have been responsible. Failure of Fontan circulation leads to systemic venous hypertension and exhaustion of venous compliance. ${ }^{3}$ Experimental models have identified systemic venous compliance as a critical determinant of VAD performance. ${ }^{4}$ The superiority of BIVAD support, as provided in this case, over systemic VAD support with medical management of the pulmonary circuit remains to be determined.

The cause of increased ventricular end diastolic pressures is unclear. It might be related to volume load caused by aortopulmonary collaterals or to intrinsic myocardial disease. The second explanation is more likely because augmentation of left VAD output did not significantly reduce pressures.

Despite these difficulties, it is unlikely that ECMO would have offered this patient opportunity for transplantation after 28 days of mechanical support. This experience identifies some of the unique physiologic and anatomic factors associated with mechanical ventricular assistance in single ventricles.

\section{References}

1. Booth KL, Roth SJ, Thiagarajan RR, Almodovar MC, del Nido PJ, Laussen PC. Extracorporeal membrane oxygen support of the Fontan and bidirectional Glenn circulations. Ann Thorac Surg. 2004;77: 1341-8.

2. Stiller B, Hetzer R, Weng Y, Hummel M, Hennig E, Nagdyman N, et al. Heart Transplantation in children after mechanical circulatory support with pulsatile pneumatic assist device. J Heart Lung Transplant. 2003;22:1201-8.

3. Kelly JR, Mack JW, Fahey JT. Diminished venous vascular capacitance in patients after with univentricular hearts after the Fontan operation. Am J Cardiol. 1995;76:158-63.

4. Pekkan K, Frakes D, De Zelicourt D, et al. Coupling pediatric ventricular assist devices to the Fontan circulation: simulations with a lumped parameter model. ASAIO J. 2005;51:618-28. 